\title{
Polypharmacy and specific comorbidities in university primary care settings
}

Carole E Aubert ${ }^{\mathrm{a}}$ (caroleelodie.aubert@insel.ch), Sven Streit ${ }^{\mathrm{b}}$ (sven.streit@biham.unibe.ch), Bruno Da Costa $^{\mathrm{b}}$ (bruno.dacosta@biham.unibe.ch), Tinh-Hai Collet ${ }^{\mathrm{c}, \mathrm{d}}$ (tinh-hai.collet@chuv.ch), Jacques Cornuz (jacques.cornuz@chuv.ch), Jean-Michel Gaspoz ${ }^{\dagger}$ (jean-michel.gaspoz@hcuge.ch), Doug Bauer ${ }^{9}$ (dbauer@psg.ucsf.edu), Drahomir Aujesky ${ }^{\mathrm{a}}$ (drahomir.aujesky@insel.ch), Nicolas Rodondi ${ }^{\mathrm{a}, \mathrm{b}}$ (nicolas.rodondi@insel.ch).

Authors affiliations: ${ }^{a}$ Department of General Internal Medicine, Inselspital, Bern University Hospital, University of Bern, Switzerland; ' Institute of Primary Health Care BIHAM, University of Bern, Switzerland; 'Service of Endocrinology, Diabetes and Metabolism, University Hospital of Lausanne, Switzerland; 'University of Cambridge Metabolic Research Laboratories, Wellcome Trust-MRC Institute of Metabolic Science, Addenbrooke's Hospital, Cambridge, UK; ${ }^{e}$ Department of Ambulatory Care and Community Medicine, University of Lausanne, Switzerland; 'Department of Community and General Medicine, Geneva University Hospital, Geneva, Switzerland; ${ }^{9}$ Departments of Medicine and Epidemiology and Biostatistics, University of California, San Francisco, United States of America.

Corresponding Author: Dr Carole E Aubert, Department of General Internal Medicine, Inselspital, University Hospital of Bern, 3010 Bern, Switzerland; e-mail: caroleelodie.aubert@insel.ch; tel: +41 (0)31 63241 63; fax: +41(0)31632 8885 .

Running heading: polypharmacy and comorbidities

Keywords: comorbidities, inappropriate prescribing, multimorbidity, pharmacoepidemiology, polypharmacy.

Abbreviations: $\mathrm{BMI}$, body mass index, $\mathrm{Cl}$, confidence interval; IRR, incidence rate ratios; OR, odds ratio; PIP, potentially inappropriate prescribing; PPO, potentially prescribing omission; SD, standard deviation; START, Screening Tool to Alert doctors to Right Treatment; STOPP, Screening Tool of Older People's Prescriptions.

Word count: 3516

Number of tables: 4

Number of appendices: 1
Abstract word count: 248

Number of figures: 1 


\section{Abstract}

\section{Aims}

Polypharmacy is associated with adverse events and multimorbidity, but data are limited on its association with specific comorbidities in primary care settings. We measured the prevalence of polypharmacy and inappropriate prescribing, and assessed the association of polypharmacy with specific comorbidities.

\section{Methods}

We did a cross-sectional analysis of 1002 patients aged 50-80 years followed in Swiss university primary care settings. We defined polypharmacy as $\geq 5$ long-term prescribed drugs and multimorbidity as $\geq 2$ comorbidities. We used logistic mixed-effects regression to assess the association of polypharmacy with the number of comorbidities, multimorbidity, specific sets of comorbidities, potentially inappropriate prescribing (PIP) and potential prescribing omission (PPO). We used multilevel mixed-effects Poisson regression to assess the association of the number of drugs with the same parameters.

\section{Results}

Patients (mean age 63.5 years, $67.5 \% \geq 2$ comorbidities, $37.0 \% \geq 5$ drugs) had a mean of 3.9 (range 0 17) drugs. Age, BMI, multimorbidity, hypertension, diabetes mellitus, chronic kidney disease, and cardiovascular diseases were independently associated with polypharmacy. The association was particularly strong for hypertension (OR $8.49,95 \% \mathrm{Cl} 5.25-13.73)$, multimorbidity (OR $6.14,95 \% \mathrm{Cl} 4.16-$ 9.08), and oldest age (75-80 years: OR $4.73,95 \% \mathrm{Cl} 2.46-9.10$ vs.50-54 years). The prevalence of PPO was $32.2 \%$ and PIP was more frequent among participants with polypharmacy $(9.3 \%$ vs. $3.2 \%$, $\mathrm{p}<0.006)$.

\section{Conclusions}

Polypharmacy is common in university primary care settings, is strongly associated with hypertension, diabetes mellitus, chronic kidney disease and cardiovascular diseases, and increases potentially inappropriate prescribing. Multimorbid patients should be included in further trials for developing adapted guidelines and avoiding inappropriate prescribing. 


\section{Introduction}

With the increasing life expectancy worldwide, a higher proportion of individuals not only get older [1], but are also more likely to develop multiple chronic conditions [2-4]. Most chronic conditions (comorbidities) are covered by disease-specific clinical guidelines using a single disease framework; this leads physicians to recommend drug treatments for each condition separately, which may lead to polypharmacy and drug-drug and drug-disease interactions [5]. In addition, to lower the risk of developing future medical conditions, research in preventive medicine has uncovered multiple risk factors, particularly in cardiovascular medicine, that also need treatment, thus increasing the number of people on regular multiple drug therapy [6, 7]. Furthermore, patients are often seen by multiple specialist physicians who prescribe drugs that primary care physicians are often reluctant to stop [8].Polypharmacy, commonly defined as the concurrent use of 5 or more long-term prescribed drugs, is frequent and increasing in prevalence [4, 7, 9-14]. The use of multiple drugs is associated with potential unforeseen medical consequences, such as adverse drug events, drug monitoring errors, unplanned hospitalizations, and sometimes fatal outcomes [5, 15-19]. The risk of drug-drug interaction increases with the number of prescribed drugs: $13 \%$ of patients on 2 concurrent drugs experience drug-drug interaction, but this risk rises to $38 \%$ for those on 5 drugs and $82 \%$ for those on $\geq 7$ drugs [20]. Moreover, polypharmacy is associated with poor adherence, lower physical and social function, higher healthcare costs, and decreased quality of life $[13,16,19]$. Additionally, inappropriate prescribing, including both over- (potentially inappropriate prescribing [PIP]) and underprescription (potential prescribing omission [PPO]) is also associated with poor outcome, such as increase in adverse drug events [21]. While polypharmacy is relatively well defined, the definition of multimorbidity is not consistent in the literature; a common definition is 2 or more comorbidities [3].

Prior epidemiological studies conducted in several other countries found a prevalence of polypharmacy ranging from 12 to $48 \%$ in patients aged 50 years or older $[9,10,13,14,22]$, but data remain limited on associations between polypharmacy and specific comorbidities, like cardiovascular ones [13]. In Switzerland, a country with universal healthcare coverage, only one study assessed the prevalence of polypharmacy and PIP, based on claims data from a health insurer company without clinical information on diagnosis. Except for this study, data on PIP and PPO in Switzerland are limited, with studies including only hospitalized geriatric [23] or mentally-ill patients [24].

We therefore aimed to measure the prevalence of polypharmacy, PIP and PPO in university primary care settings, and to assess the association of polypharmacy with specific comorbidities, in order to uncover subgroups of patients at higher risk of polypharmacy. 


\section{Material and methods}

\section{Study population}

We abstracted medical records from 1002 randomly selected patients followed for at least one year by primary care physicians in all but one Swiss university primary care clinics (Basel, Geneva, Lausanne and Zurich) in a retrospective cohort study, as previously described [25]. For this analysis, we used cross-sectional data of the baseline visit. These community-dwelling patients were randomly identified from electronic administrative data of all patients aged 50 to 80 years and followed in 2005-2006. The selection was limited to this age group to ensure a high prevalence of cardiovascular risk factors and other conditions that are targeted by preventive care and medical treatment. About $90 \%$ of the patients were cared for by residents in general internal medicine supervised by senior physicians. The remaining $10 \%$ were cared by senior physicians directly.

We initially identified 1889 patients, among which 54 charts could not be found, probably because the patients had left the clinic for another ambulatory practice. We excluded 125 patients because they had no outpatient visit to a primary care physician, and 117 that were followed only in a specialized care setting during this period. In order to ensure adequate time and information to assess preventive care, we excluded another 591 patients who had less than one year follow-up in the university primary care setting during the review period.

\section{Definitions of polypharmacy and multimorbidity}

We recorded only long-term prescribed drugs at the first visit of the review period; prescriptions for acute conditions, like antibiotics or temporary painkillers, were not taken into account. Similarly to previous studies, we defined polypharmacy as 5 or more long-term prescribed drugs $[9,12,14,26,27]$. We found no consistent definition to select comorbidities in prior scientific literature [28]. The length of comorbidity lists ranged from 7 to 46 different comorbidities [13, 29-31]. We therefore established a new list including 17 comorbidities (Table A), as previously described [32], based on a large study by Higashi et al. [33] and on the Charlson index [34]. We added psychiatric conditions (e.g. schizophrenia, depression) as an important comorbidity [35], based on a consensus of the above mentioned references and between the authors. Additionally, we defined specific subgroups of comorbidities: 1) cardiovascular diseases: history of transient ischemic attack, cerebral vascular accident, coronary artery disease, angina, myocardial infarction, congestive heart failure and/or peripheral vascular disease; 2) chronic pulmonary diseases: chronic obstructive pulmonary disease, asthma, sleep apnea syndrome, 
sarcoidosis, pulmonary hypertension, bronchiectases, interstitial pulmonary disease and/or global respiratory insufficiency; 3) psychiatric diseases: depression, bipolar disorder, psychosis, schizophrenia and/or pervasive development disorder. For sensitivity analyses, we used subcategories of cardiovascular disease (cerebral vascular disease, ischemic heart disease, heart failure). As did others $[3,29]$, we defined multimorbidity as the presence of 2 or more of these comorbidities [32], but also assessed the number of comorbidities as a count variable.

\section{Potentially inappropriate prescribing and potentially prescribing omission}

PIP and PPO were measured using the Screening Tool of Older People's Prescriptions (STOPP) and the Screening Tool to Alert doctors to Right Treatment (START) criteria [36]. As the criteria were developed for individuals aged $\geq 65$ years, we applied them to this subgroup of our patients, and then performed a sensitivity analysis including our whole population. As we had detailed clinical information on cardiovascular disease and cardiovascular risk factors, we only applied the STOPP/START criteria for cardiovascular and anti-diabetic drugs when all detailed clinical information was available. Therefore, we applied 7 STOPP (i.e. A3, B3, B6, C1, C7, J1, J2) and 4 START (i.e. A3, A4, A5, A7) criteria related to these drugs. One author (CEA) checked the whole database for PIP and PPO. A 5\% random sample was checked for accuracy by a second author (SS). The agreement between the 2 reviewers was 98.0\% and the $2.0 \%$ disagreement was solved by discussion. PIP and PPO were defined as the percentage of patients with at least 1 unfulfilled STOPP and START criteria, respectively.

\section{Statistical Analyses}

We counted the number of drugs as a whole $(0,1,2,3,4,5,6,7,8,9, \geq 10)$, as well as stratified by 5year age groups and by the number of comorbidities $(0,1,2,3-4,5-6, \geq 7)$. We compared baseline characteristics between patients with and those without polypharmacy using t-test and chi-square test where appropriate.

We used a logistic mixed-effects regression model, crude and adjusted for age, gender, civil status and occupation, to assess the association of polypharmacy with the number of comorbidities, presence of multimorbidity, smoking status, body mass index (BMI), specific comorbidities, subgroups of comorbidities (psychiatric diseases, dementia, cardiovascular diseases, diabetes mellitus, hypertension, chronic pulmonary diseases, cancer and chronic kidney disease), PIP and PPO. Results were presented as odds ratio $(\mathrm{OR})$ with $95 \%$ confidence intervals $(\mathrm{Cl})$. 
We used a multilevel mixed-effects Poisson regression model, crude and adjusted for the same parameters, to assess the association between the number of drugs as a count variable with the same variables as in the previous model. Results were presented as incidence rate ratios (IRR) with $95 \% \mathrm{Cl}$. We used the mixed-effects models to account for the clustering of patients within the different treating physicians and treatment centers. We performed all statistical analyses using STATA release 13.1 (StataCorp, College Station, TX). All p-values were 2-sided at a 0.05 level of significance.

\section{Results}

\section{Patients characteristics}

Table 1 shows baseline characteristics of the study population by presence or absence of polypharmacy. Mean age (standard deviation [SD]) was 63.5 (8.3) years and 44.4\% were women. Most patients (55.9\%) were Swiss and $37.9 \%$ were retired. The majority $(67.5 \%)$ of patients had multimorbidity and the mean number of comorbidities was 2.6 , ranging from 0 to 10 . Almost every patient $(91.1 \%)$ had at least $1 \mathrm{drug}, 37.0 \%$ had polypharmacy and $4.1 \%$ had at least 10 drugs. The maximum number of different drugs taken by a single patient was 17 .

The association between polypharmacy, number of drugs and age

Figure 1a shows the percentage of patients on a particular number of drugs according to age group. Patients with polypharmacy were significantly older than patients on less than 5 drugs $(p<0.0001$, Table 1). The prevalence of polypharmacy was $20.8 \%(41 / 197)$ in the youngest age group (50-54 years), $45.6 \%(194 / 426)$ in the patients aged 65 years or older, and 54.8\% (63/115) in the oldest age group (7580 years). The oldest age group had the highest odds for polypharmacy compared to the youngest age group in adjusted analysis (OR 4.73,95\% Cl 2.46-9.10, Table 2). In the highest age group, the number of drugs was $29 \%$ higher than in the lowest age group (IRR $1.29,95 \% \mathrm{Cl} 1.07-1.56$, Table 3).

\section{The association of polypharmacy, number of drugs and comorbidities}

The number of drugs increased significantly with the number of comorbidities. In patients with 4 or more comorbidities, all but 2 patients (9.2\%) had at least 1 drug. Among the patients with at least 7 comorbidities, $84.9 \%$ had polypharmacy (Figure 1b). This association remained significant in multivariate analyses; even after adjustment for demographics, patients with multimorbidity had a far higher odds for polypharmacy (OR 6.14, 95\% Cl 4.16-9.08, Table 2) and an increased number of drugs 
(IRR 1.91, 95\% Cl 1.72-2.13, Table 3) compared to patients without multimorbidity. For each additional comorbidity, patients were more likely to have more prescribed drugs (IRR 1.18, 95\% $\mathrm{Cl} 1.15-1.20$ ).

Hypertension had the strongest association with polypharmacy (OR 8.49, 95\% Cl 5.25-13.73) and the number of drugs (IRR $2.10,95 \% \mathrm{Cl} 1.87-2.36$ ). Cardiovascular diseases, diabetes mellitus, BMI and chronic kidney disease were also independently associated with polypharmacy and the number of drugs (Tables 2 and 3). Chronic pulmonary diseases were weakly associated with the number of drugs, but not with polypharmacy (Tables 2 and 3). Psychiatric diseases, dementia and cancer were associated neither with polypharmacy nor with the number of drugs. The OR $(95 \% \mathrm{Cl})$ for polypharmacy was 2.63 (1.56-4.46) in patients with cerebral vascular disease, 3.96 (2.75-5.71) in patients with ischemic heart disease, and 14.32 (5.75-35.66) in patients with heart failure.

\section{Polypharmacy, number of drugs and other clinical variables}

Being employed was associated with a lower number of drugs when compared with other social status (on social aid, unemployed, at home, in education, or retired), and with a lower prevalence of polypharmacy when compared with being on social aid or unemployed (Tables 2 and 3). These associations were less strong after adjusting for the number of comorbidities (data not shown). Civil status was associated neither with polypharmacy nor with the number of drugs. Finally, male gender was only slightly associated with the number of drugs, but not with polypharmacy (Tables 2 and 3).

\section{Potentially inappropriate prescribing and potentially prescribing omission}

Table 4 describes the prevalence of each STOPP/START criterion in patients aged $\geq 65$ years and in the whole patient population. In patients aged $\geq 65$ years, the prevalence of PIP was $5.9 \%$; it was higher among patients with polypharmacy ( $9.3 \%$ versus $3.0 \%$ in those without, $p=0.006$, Table 1 ) and strongly associated with polypharmacy (OR $3.72,95 \% \mathrm{Cl} 1.47-9.44$, Table 2 ) and with the number of drugs (IRR $1.35,95 \% \mathrm{Cl} 1.12-1.64$, Table 3). Almost one third (32.2\%) of the patients had PPO. PPO was associated neither with polypharmacy nor with the number of drugs (Tables 2 and 3). Forty-eight patients had more than 1 PPO. Omitting antiplatelet (START criterion A3) and statin (START criterion A5) therapies with a documented history of coronary, cerebral, or peripheral vascular disease were the 2 most prevalent PPO, accounting for $70.7 \%$ of the PPOs. We found similar results in the whole study population (Tables 2, 3 and 4). 


\section{Discussion}

In this random sample of primary care patients aged $50-80$ years, we found that $37 \%$ had polypharmacy, and $4 \%$ received 10 drugs or more. The prevalence of PIP was significantly higher among patients with polypharmacy. Multimorbidity, age, and specific comorbidities, such as hypertension, diabetes mellitus, chronic kidney disease and cardiovascular diseases, were associated with polypharmacy, while other subgroups of comorbidities (psychiatric diseases, dementia, chronic pulmonary diseases, cancer) were not. The association was particularly strong for hypertension.

The prevalence of polypharmacy in our study was consistent with prior epidemiological studies conducted in other high income countries in patients aged 50 years or older: a large Swedish study found a prevalence of polypharmacy of $12-38 \%$ in the age group 50-79 years [9], while it ranged from 13 to $48 \%$ for the same age range in a study using electronic primary care records in Scotland [13], and was $29 \%$ in patients aged $57-85$ years in the USA [14]. When focusing on patients aged 65 years or older, the prevalence of polypharmacy in our study (46\%) was also consistent with previous data from an Italian community-dwelling population (46\%) [22].

The strong association of multimorbidity and the number of comorbidities with polypharmacy and the number of drugs is consistent with previous data $[13,14,31]$. This may reflect the disease-specific guidelines that are still usually applied for initiating drug treatments. However, patients with multimorbidity are often excluded from, and less than $5 \%$ explicitly included in randomized controlled trials on which these recommendations are based [37]; thus, applying them to these patients may be inappropriate $[19,38]$. The strong association between PIP and polypharmacy is consistent with previous data using the same criteria for PIP [23]. This observation highlights the importance to reconsider each prescription in patients receiving polypharmacy. For this purpose, the STOPP/START criteria may help [36, 39]; however, as the application of the whole criteria set is time-consuming and therefore difficult to implement in everyday clinical practice, software solutions are under development. Finally, physician's clinical judgment and shared decision making are central in the process of prescription.

The United Kingdom Prospective Diabetes Study (UKPDS) in patients with type 2 diabetes showed that $29 \%$ of the patients needed at least 3 different drugs to reach a blood pressure target of $<150 / 85 \mathrm{mmHg}$ [40], while the recommended goal in this population is far lower $(<130 / 80 \mathrm{mmHg})$ [41]. Additionally, because hypertension, diabetes mellitus and chronic kidney disease are strongly related to cardiovascular diseases, patients with these comorbidities often receive additional drugs recommended in both primary and secondary prevention (e.g. aspirin, statins) [19, 42-44]. The association of these 
cardiovascular risk factors and cardiovascular diseases with polypharmacy is consistent with previous data $[13,45]$. Interestingly, we found a stronger association of polypharmacy with hypertension than with cardiovascular disease. The interpretation of this finding is limited by our broad classification of cardiovascular disease, which was associated with some heterogeneity (e.g. stronger association of polypharmacy with heart failure than with stroke).

Surprisingly, we found no association between polypharmacy and psychiatric disorders. This probably reflects the reality of patients cared in ambulatory general internal medicine. Psychiatric conditions that are mostly managed with drugs (e.g. schizophrenia) [46] were indeed rather rare (6\% of the patients having a psychiatric condition in our study had schizophrenia), while more prevalent conditions like personality disorder ( $25 \%$ of the patients having a psychiatric condition in our study) are often managed without any drug as first line therapy. On the other hand, patients followed in specialized psychiatric settings may have more severe conditions needing multiple medications, thus polypharmacy may be more prevalent among them. We also found no association with dementia, but our study included only 24 patients with this condition. Preventive drugs might have been discontinued in these patients with formally diagnosed dementia, as dementia is associated with shortened life expectancy and decreased quality of life [47].

In our study, there was no significant association between cancer and polypharmacy, which is consistent with the study by Payne et al. (12) that found a similar mean number of drugs among this subgroup of patients (4 drugs). On the opposite, a review of previous studies in patients with advanced cancer showed a high prevalence of polypharmacy among them [48]. This discrepancy is probably due to different settings (in-hospital versus ambulatory) and study population (advanced versus not advanced cancer).

Patients who were unemployed, receiving social aid, at home, in education or retired, were prescribed a higher number of drugs than patients that were employed. Interestingly, this association was stronger for patients unemployed or receiving social aid than for patients being at home, in education or retired. This finding may be partially explained by a higher number of comorbidities, as the association of occupation status and polypharmacy was weakened by adjusting for the number of comorbidities. This is consistent with data showing a higher prevalence of multimorbidity in the most deprived population, among which multimorbidity would occur on average 10 to 15 years earlier [3]. However, as this association didn't disappear after adjustment for the number of comorbidities, we can hypothesize additional explanations for this finding: deprived patients may have lower income and/or education, 
which has been associated with polypharmacy [10, 13, 49]; they may also more likely consult with a prescription purpose, as suggested previously [49].

Although the community-dwelling individuals in our study differed from older frail nursing home residents, those with multimorbidity are at higher risk of polypharmacy as they become older. Although the patterns of drugs are different in nursing home and in the community, e.g. with a higher number of pain-killers and psychotropic drugs [50-52], optimizing medication in the community-dwelling individuals is also central in order to optimize care and reduce polypharmacy.

There are some limitations to our study. First, our results are based on retrospective medical chart review, with potential underreporting; however, a previous study comparing process-based quality scores using standardized patients, clinical vignettes and abstraction of medical charts found that measurement of quality of care using abstraction of medical charts was about $5 \%$ lower than using clinical vignettes and $10 \%$ lower than using standardized patients [53]. Second, we restricted our analyses to patients aged 50 to 80 years and can therefore not draw conclusions for younger or older patients. Third, as we could apply a subset of the STOPP/START criteria only, we could not compare the prevalence of PIP and PPO with data of other previous studies. Fourth, we conducted only a crosssectional analysis without assessing the impact of polypharmacy and STOPP/START criteria on patient's related health outcomes Finally, our results may not be totally generalizable to primary care settings in general for several reasons: we could not assess other parameters of socioeconomic status, such as income and education, because of the lack of reliable information on these variables in the medical charts, and, in Switzerland, there are generally more forced migrants and patients with lower socioeconomic status in university primary care settings, which has been associated with an earlier occurrence of multimorbidity [3]. The prevalence of some comorbidities, like hypertension, may also be higher in these settings [32]. Furthermore, almost all patients were cared by residents at the end of their postgraduate training, who may be more adherent to medical guidelines [25]. 


\section{Learning points:}

$>$ In university primary care settings, $37.0 \%$ of patients have $\geq 5$ chronic drugs $(4.1 \% \geq 10)$, and potentially inappropriate prescribing is more frequent among participants with polypharmacy $(11.9 \%$ vs. $3.7 \%, p<0.0001)$.

> Several specific comorbidities, particularly hypertension, diabetes mellitus, chronic kidney disease and cardiovascular diseases, are strongly associated with polypharmacy.

> Future trials should include multimorbid patients, in order to develop prescription guidelines adapted to this population at particular high risk of polypharmacy and potentially inappropriate prescribing.

\section{Conclusions and clinical implications}

In this random sample of primary care patients, we found that polypharmacy was highly prevalent in university primary care settings and strongly associated with age, multimorbidity, the number of comorbidities, and specific comorbidities, particularly hypertension, diabetes mellitus, chronic kidney disease, and cardiovascular diseases. This is clinically relevant, given the association of polypharmacy with adverse consequences, particularly in patients with multimorbidity [5]. Given that the prevalence of polypharmacy and multimorbidity will very probably further increase in the coming years, and that PIP is associated with polypharmacy, further randomized trials including multimorbid patients are needed in order to develop guidelines adapted to this particular population to help avoiding PIP and adverse drug events. As polypharmacy, the risk for drug-drug interactions and their associated negative consequences are significantly increased among the oldest old patients because of frailty and their higher number of comorbidities [54], future studies should also plan to include oldest old patients, i.e. those aged more than 80 years.Waiting for any new specific recommendation for multimorbid elderly, specific indications for each drug should be very carefully reviewed, particularly in those patients. In the meantime, we suggest that the process of prescription relies on the use of criteria developed to avoid PIP and PPO (e.g. the STOPP/START criteria [36, 39]), accounting for physician's clinical judgment, estimated patient's life expectancy and patient's preferences. 


\section{Authors' contribution}

Dr Carole E Aubert had full access to all of the data in the study, takes responsibility for the integrity of the data and the accuracy of the data analysis and is the guarantor. Study concept and design: Aubert and Rodondi. Acquisition of data: Aujesky, Collet, Cornuz, Gaspoz and Rodondi. Analysis and interpretation of data: Aubert, Collet, Da Costa, Rodondi and Streit. Drafting of the manuscript: Aubert, Collet and Streit. Critical revision of the manuscript for important intellectual content: Aujesky, Bauer, Collet, Cornuz, Gaspoz, Rodondi and Streit. Statistical analysis: Da Costa and Streit. Study supervision: Rodondi.

\section{Compliance with ethical standards}

This study was approved by all local ethics committees. Because of the retrospective character of the study and the anonymity of patient data, the approving Institutional Review Boards waived the requirement of patient consent.

All authors have completed the Unified Competing Interest form at http://www.icmje.org/coi_disclosure.pdf (available on request from the corresponding author). An investigator-initiated grant from Pfizer (Switzerland) was provided only for data collection and analysis in 2005, but Pfizer had no role in the study design, topic of the manuscript, decision to publish, or preparation of the manuscript. Except for this grant, all authors declare: no support from any organization for the submitted work; no financial relationships with any organizations that might have an interest in the submitted work in the previous 3 years; no other relationships or activities that could appear to have influenced the submitted work.

\section{Acknowledgements}

Prof. N. Rodondi's research is supported by a grant from the Swiss National Science Foundation (SNSF 320030-150025) and by the project "OPERAM (OPtiminising thERapy to prevent Avoidable hospital admissions in the Multimorbid elderly") supported by the European Commission (EC) HORIZON 2020, proposal 634238, and by the Swiss State Secretariat for Education, Research and Innovation (SERI) under contract number 15.0137. The opinions expressed and arguments employed herein are those of the authors and do not necessarily reflect the official views of the EC and the Swiss government. Dr. Streit was funded in part by the Swiss University Conference and the State Secretariat for Education, Research and Innovation (SUC project P-10). Dr T-H Collet's research is supported by grants from the Swiss National Science Foundation (PBLAP3-145870, P3SMP3-155318). 


\section{References}

1. Organisation, W.H., WHO methods for life expectancy and healthy life expectancy. Global health Estimates Technical Paper WHO/HIS/HSI/GHE/2014.5.

2. Rizza, A., et al., Age- and gender-related prevalence of multimorbidity in primary care: the Swiss FIRE project. BMC Fam Pract, 2012. 13: p. 113.

3. Barnett, K., et al., Epidemiology of multimorbidity and implications for health care, research, and medical education: a cross-sectional study. Lancet, 2012. 380(9836): p. 37-43.

4. Nishtala, P.S. and M.S. Salahudeen, Temporal Trends in Polypharmacy and Hyperpolypharmacy in Older New Zealanders over a 9-Year Period: 2005-2013. Gerontology, 2015. 61(3): p. 195-202.

5. Boyd, C.M., et al., Clinical practice guidelines and quality of care for older patients with multiple comorbid diseases: implications for pay for performance. Jama, 2005. 294(6): p. 716-24.

6. Westin, S. and I. Heath, Thresholds for normal blood pressure and serum cholesterol. Bmj, 2005. $330(7506):$ p. 1461-2.

7. Silwer, L. and C.S. Lundborg, Patterns of drug use during a 15 year period: data from a Swedish county, 1988--2002. Pharmacoepidemiol Drug Saf, 2005. 14(11): p. 813-20.

8. Anthierens, S., et al., Qualitative insights into general practitioners views on polypharmacy. BMC Fam Pract, 2010. 11: p. 65.

9. Hovstadius, B., et al., Increasing polypharmacy - an individual-based study of the Swedish population 2005-2008. BMC Clin Pharmacol, 2010. 10: p. 16.

10. Guthrie, B., et al., The rising tide of polypharmacy and drug-drug interactions: population database analysis 1995-2010. BMC Med, 2015. 13: p. 74.

11. Haider, S.I., et al., Trends in polypharmacy and potential drug-drug interactions across educational groups in elderly patients in Sweden for the period 1992 - 2002. Int J Clin Pharmacol Ther, 2007. 45(12): p. 643-53.

12. Gnjidic, D., et al., Polypharmacy cutoff and outcomes: five or more medicines were used to identify community-dwelling older men at risk of different adverse outcomes. J Clin Epidemiol, 2012. 65(9): p. 989-95.

13. Payne, R.A., et al., Prevalence of polypharmacy in a Scottish primary care population. Eur J Clin Pharmacol, 2014. 70(5): p. 575-81. 
14. Qato, D.M., et al., Use of prescription and over-the-counter medications and dietary supplements among older adults in the United States. Jama, 2008. 300(24): p. 2867-78.

15. Scott, I.A., et al., Reducing inappropriate polypharmacy: the process of deprescribing. JAMA Intern Med, 2015. 175(5): p. 827-34.

16. Ahmed, B., et al., Effects of polypharmacy on adverse drug reactions among geriatric outpatients at a tertiary care hospital in Karachi: a prospective cohort study. PLoS One, 2014. 9(11): p. e112133.

17. Jyrkka, J., et al., Polypharmacy status as an indicator of mortality in an elderly population. Drugs Aging, 2009. 26(12): p. 1039-48.

18. Beer, C., et al., Quality use of medicines and health outcomes among a cohort of community dwelling older men: an observational study. Br J Clin Pharmacol, 2011. 71(4): p. 592-9.

19. Payne, R.A., et al., Is polypharmacy always hazardous? A retrospective cohort analysis using linked electronic health records from primary and secondary care. Br J Clin Pharmacol, 2014. 77(6): p. 1073-82.

20. Goldberg, R.M., et al., Drug-drug and drug-disease interactions in the ED: analysis of a highrisk population. Am J Emerg Med, 1996. 14(5): p. 447-50.

21. Tommelein, E., et al., Potentially inappropriate prescribing in community-dwelling older people across Europe: a systematic literature review. Eur J Clin Pharmacol, 2015. 71(12): p. 1415-27.

22. Franchi, C., et al., Changes in drug prescribing to Italian community-dwelling elderly people: the EPIFARM-Elderly Project 2000-2010. Eur J Clin Pharmacol, 2014. 70(4): p. 437-43.

23. Gallagher, P., et al., Prevalence of potentially inappropriate prescribing in an acutely ill population of older patients admitted to six European hospitals. Eur J Clin Pharmacol, 2011. 67(11): p. 1175-88.

24. Lang, P.O., et al., Potentially inappropriate prescribing including under-use amongst older patients with cognitive or psychiatric co-morbidities. Age Ageing, 2010. 39(3): p. 373-81.

25. Collet, T.H., et al., The quality of primary care in a country with universal health care coverage. J Gen Intern Med, 2011. 26(7): p. 724-30.

26. Blozik, E., et al., Polypharmacy and potentially inappropriate medication in the adult, community-dwelling population in Switzerland. Drugs Aging, 2013. 30(7): p. 561-8.

27. Leiss, W., et al., Polypharmacy is associated with an increased risk of bleeding in elderly patients with venous thromboembolism. J Gen Intern Med, 2015. 30(1): p. 17-24. 
28. Aarts, S., et al., The effect of multimorbidity on health related functioning: temporary or persistent? Results from a longitudinal cohort study. J Psychosom Res, 2012. 73(3): p. 211-7.

29. Fortin, M., et al., Prevalence estimates of multimorbidity: a comparative study of two sources. BMC Health Serv Res, 2010. 10: p. 111.

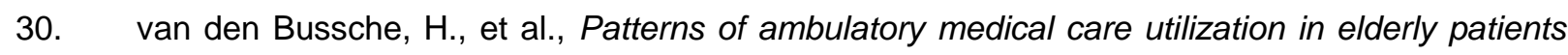
with special reference to chronic diseases and multimorbidity--results from a claims data based observational study in Germany. BMC Geriatr, 2011. 11: p. 54.

31. Gallacher, K.I., et al., Stroke, multimorbidity and polypharmacy in a nationally representative sample of 1,424,378 patients in Scotland: implications for treatment burden. BMC Med, 2014. 12: p. 151.

32. Streit, S., et al., Multimorbidity and quality of preventive care in Swiss university primary care cohorts. PLoS One, 2014. 9(4): p. e96142.

33. Higashi, T., et al., Relationship between number of medical conditions and quality of care. $\mathrm{N}$ Engl J Med, 2007. 356(24): p. 2496-504.

34. Charlson, M.E., et al., A new method of classifying prognostic comorbidity in longitudinal studies: development and validation. J Chronic Dis, 1987. 40(5): p. 373-83.

35. Piette, J.D., et al., Veterans Affairs research on health information technologies for diabetes self-management support. J Diabetes Sci Technol, 2008. 2(1): p. 15-23.

36. O'Mahony, D., et al., STOPP/START criteria for potentially inappropriate prescribing in older people: version 2. Age Ageing, 2015. 44(2): p. 213-8.

37. Jadad, A.R., et al., Consideration of multiple chronic diseases in randomized controlled trials. JAMA, 2011. 306(24): p. 2670-2.

38. Guthrie, B., et al., Adapting clinical guidelines to take account of multimorbidity. Bmj, 2012. 345: p. e6341.

39. Beers, M.H., et al., Explicit criteria for determining inappropriate medication use in nursing home residents. UCLA Division of Geriatric Medicine. Arch Intern Med, 1991. 151(9): p. 1825-32.

40. Cost effectiveness analysis of improved blood pressure control in hypertensive patients with type 2 diabetes: UKPDS 40. UK Prospective Diabetes Study Group. Bmj, 1998. 317(7160): p. 720-6.

41. Williams, B., et al., Guidelines for management of hypertension: report of the fourth working party of the British Hypertension Society, 2004-BHS IV. J Hum Hypertens, 2004. 18(3): p. 13985. 
42. Yang, M., et al., Does residing in urban or rural areas affect the incidence of polypharmacy among older adults in western China? Arch Gerontol Geriatr, 2015. 60(2): p. 328-33.

43. Corsonello, A., et al., Polypharmacy in elderly patients at discharge from the acute care hospital. Ther Clin Risk Manag, 2007. 3(1): p. 197-203.

44. Diez-Manglano, J., et al., Polypharmacy in patients hospitalised for acute exacerbation of COPD. Eur Respir J, 2014. 44(3): p. 791-4.

45. Nobili, A., et al., Polypharmacy, length of hospital stay, and in-hospital mortality among elderly patients in internal medicine wards. The REPOSI study. Eur J Clin Pharmacol, 2011. 67(5): p. $507-19$

46. Correll, C.U. and J.A. Gallego, Antipsychotic polypharmacy: a comprehensive evaluation of relevant correlates of a long-standing clinical practice. Psychiatr Clin North Am, 2012. 35(3): p. $661-81$

47. Hongisto K, V.S., Martikainen J, Hallikainen I, Välimäki T, Hartikainen S, Suhonen J, Koivisto AM., Self-Rated and Caregiver-Rated Quality of Life in Alzheimer Disease with a Focus on Evolving Patient Ability to Respond to Questionnaires: 5-Year Prospective ALSOVA Cohort Study. Am J Geriatr Psychiatry, 2015. S1064-7481(15)00206-7. .

48. LeBlanc, T.W., et al., Polypharmacy in patients with advanced cancer and the role of medication discontinuation. Lancet Oncol, 2015. 16(7): p. e333-41.

49. Mayer, S. and A. Osterle, Socioeconomic determinants of prescribed and non-prescribed medicine consumption in Austria. Eur J Public Health, 2014.

50. Jacquin-Piques, A., et al., Psychotropic Drug Prescription in Patients with Dementia: Nursing Home Residents Versus Patients Living at Home. J Alzheimers Dis, 2015. 49(3): p. 671-80.

51. Jokanovic, N., et al., Why is polypharmacy increasing in aged care facilities? The views of Australian health care professionals. J Eval Clin Pract, 2016.

52. Onder, G., et al., Polypharmacy in nursing home in Europe: results from the SHELTER study. J Gerontol A Biol Sci Med Sci, 2012. 67(6): p. 698-704.

53. Peabody, J.W., et al., Comparison of vignettes, standardized patients, and chart abstraction: a prospective validation study of 3 methods for measuring quality. Jama, 2000. 283(13): p. 171522.

54. Sharifi, H., M.A. Hasanloei, and J. Mahmoudi, Polypharmacy-induced drug-drug interactions; threats to patient safety. Drug Res (Stuttg), 2014. 64(12): p. 633-7. 
Table 1. Patient characteristics: overall and by presence or absence of polypharmacy.

\begin{tabular}{|c|c|c|c|c|}
\hline Characteristics & $\begin{array}{l}\text { Overall } \\
(\mathrm{n}=1002)^{\mathrm{a}}\end{array}$ & $\begin{array}{l}\text { 0-4 drugs } \\
(\mathrm{n}=631,63.0 \%)^{\mathbf{a}}\end{array}$ & $\begin{array}{l}\geq 5 \text { drugs } \\
(n=371,37.0 \%)^{a}\end{array}$ & p-value \\
\hline \multicolumn{5}{|l|}{$\begin{array}{l}\text { Age, mean (SD) } \\
\text { Age groups, } n \text { (\% per column) }\end{array}$} \\
\hline $\begin{array}{l}\text { Age groups, } \\
50-54\end{array}$ & $197(19.7)$ & $156(24.7)$ & $41(11.0)$ & $<0.0001$ \\
\hline $55-59$ & $193(19.3)$ & $125(19.8)$ & 68 (18.3) & $<0.0001$ \\
\hline $60-64$ & $186(18.6)$ & $118(18.7)$ & $68(18.3)$ & $<0.0001$ \\
\hline $65-69$ & $183(18.3)$ & $106(16.8)$ & $77(20.8)$ & 0.03 \\
\hline $70-74$ & $128(12.3)$ & $74(11.7)$ & $54(14.6)$ & 0.08 \\
\hline $75-80$ & $115(11.5)$ & $52(8.2)$ & $63(17.0)$ & 0.31 \\
\hline Women, $\mathrm{n}$ (\% per column) & $445(44.4)$ & $297(47.1)$ & $148(39.9)$ & 0.03 \\
\hline $\begin{array}{l}\text { Civil status, } \mathrm{n} \text { (\% per column) } \\
\text { married } \\
\text { single } \\
\text { divorced / separated } \\
\text { widow/-er }\end{array}$ & $\begin{array}{l}506(51.0) \\
151(15.2) \\
233(23.5) \\
103(10.4) \\
\end{array}$ & $\begin{array}{l}314(50.3) \\
101(16.2) \\
150(24.0) \\
59(9.5)\end{array}$ & $\begin{array}{l}192(52.0) \\
50(13.6) \\
83(22.5) \\
44(11.9) \\
\end{array}$ & $\begin{array}{l}<0.0001 \\
<0.0001 \\
<0.0001 \\
0.14\end{array}$ \\
\hline \multicolumn{5}{|l|}{ Occupation, n (\% per column) } \\
\hline Employed & $285(29.0)$ & $225(36.3)$ & $60(16.6)$ & $<0.0001$ \\
\hline Social aid & $109(11.1)$ & $60(9.7)$ & 49 (13.5) & 0.29 \\
\hline Unemployed & $101(10.3)$ & $51(8.2)$ & $50(13.8)$ & 0.92 \\
\hline At home or in education & $115(11.7)$ & 79 (12.7) & $36(9.9)$ & $<0.0001$ \\
\hline Retired & $372(37.9)$ & $205(33.1)$ & $167(46.1)$ & 0.049 \\
\hline \multicolumn{5}{|l|}{ Legal status, $\mathrm{n}$ (\% per column) } \\
\hline Swiss & $560(55.9)$ & $362(59.4)$ & $198(55.0)$ & $<0.0001$ \\
\hline Resident permit & $325(32.4)$ & $183(30.2)$ & $142(39.4)$ & 0.02 \\
\hline Forced migrant & $81(8.1)$ & $61(10.1)$ & $20(5.6)$ & 0.002 \\
\hline \multicolumn{5}{|l|}{ Number of outpatients visits over 2 years } \\
\hline $\begin{array}{l}\text { Median (interquartile range) } \\
\text { Range, minimum-maximum }\end{array}$ & $\begin{array}{l}10(7-15) \\
2-63\end{array}$ & $\begin{array}{l}9(6-13) \\
2-41\end{array}$ & $\begin{array}{l}12(9-17) \\
3-63\end{array}$ & $<0.0001$ \\
\hline Never smoked, $\mathrm{n}$ (\% per column) & $283(41.0)$ & $194(44.3)$ & $89(35.3)$ & 0.02 \\
\hline BMI, mean (SD) & $28.8(5.6)$ & $27.9(5.3)$ & $30.4(5.8)$ & $<0.0001$ \\
\hline $\begin{array}{l}\text { Comorbidities }^{c} \\
\text { mean (SD) } \\
\geq 2 \text { comorbidities, } n \text { (\% per column) }\end{array}$ & $\begin{array}{l}2.6(1.9) \\
676(67.5)\end{array}$ & $\begin{array}{l}1.9(1.4) \\
346(54.8)\end{array}$ & $\begin{array}{l}3.7(2.0) \\
330(89.0)\end{array}$ & $\begin{array}{l}<0.0001 \\
<0.0001\end{array}$ \\
\hline \multicolumn{5}{|l|}{ Specific subgroups $^{\mathrm{d}}, \mathrm{n}$ (\% per column) } \\
\hline Psychiatric diseases $^{\mathrm{e}}$ & $294(29.3)$ & $180(28.5)$ & $114(30.7)$ & 0.46 \\
\hline Dementia & $24(2.4)$ & $14(2.2)$ & $10(2.7)$ & 0.63 \\
\hline Cardiovascular diseases ${ }^{f}$ & $364(36.3)$ & $154(24.4)$ & $210(56.6)$ & $<0.0001$ \\
\hline Diabetes mellitus & $292(29.1)$ & $113(17.9)$ & $179(48.2)$ & $<0.0001$ \\
\hline Hypertension & $753(75.1)$ & $406(64.3)$ & 347 (93.5) & $<0.0001$ \\
\hline Chronic pulmonary diseases ${ }^{g}$ & $261(26.1)$ & $148(23.4)$ & $113(30.5)$ & 0.02 \\
\hline Cancer & $142(14.2)$ & $84(13.3)$ & $58(15.6)$ & 0.31 \\
\hline Chronic kidney disease & $167(16.7)$ & $61(9.7)$ & $106(28.6)$ & $<0.0001$ \\
\hline \multicolumn{5}{|l|}{ Inappropriate prescribing } \\
\hline Patients aged $\geq 65$ years $^{a}$ & & & & \\
\hline PIP, n (\% per column) & $25(5.6)$ & $7(3.0)$ & $18(9.3)$ & 0.006 \\
\hline PPO, n (\% per column) & $137(32.2)$ & $80(34.5)$ & $57(29.4)$ & 0.26 \\
\hline Whole population & & & & \\
\hline PIP, n (\% per column) & $67(6.7)$ & $23(3.7)$ & $44(11.9)$ & $<0.0001$ \\
\hline PPO, n (\% per column) & $275(27.5)$ & $176(28.0)$ & $98(26.4)$ & 0.56 \\
\hline
\end{tabular}

Abbreviations: PIP, potentially inappropriate prescribing; PPO, potentially prescribing omission; SD, standard deviation; STOPP, Screening Tool of Older People's Prescriptions; START, Screening Tool to Alert doctors to Right Treatment.

${ }^{a}$ For the subset of patients aged $\geq 65$ years that were applied the STOPP/START criteria: total n was 426, with 194 (45.6\% with polypharmacy and $232(54.5 \%)$ without polypharmacy.

${ }^{\mathrm{b}} \mathrm{p}$-value for comparison between patients with and without polypharmacy.

${ }^{c}$ list of 17 comorbidities listed in Appendix table, full description in [32].

${ }^{d}$ record of ever having the listed comorbidity

${ }^{\mathrm{e}}$ depression, bipolar disorder, psychosis, schizophrenia, pervasive development disorder.

${ }^{\dagger}$ history of transient ischemic attack, cerebral vascular accident, coronary artery disease, angina, myocardial infarction, congestive heart failure or peripheral vascular disease.

${ }^{\mathrm{g}}$ chronic obstructive pulmonary disease, asthma, sleep apnea syndrome, sarcoidosis, pulmonary hypertension, bronchiectases, interstitial pulmonary disease or global respiratory insufficiency. 
Table 2. Multivariate mixed-effects logistic regression analysis for the association between patient characteristics and polypharmacy.

\begin{tabular}{|c|c|c|}
\hline \multirow[t]{2}{*}{ Variable } & \multicolumn{2}{|c|}{ Polypharmacy ( $\geq 5$ drugs) } \\
\hline & OR & $95 \% \mathrm{Cl}$ \\
\hline \multicolumn{3}{|l|}{ Age (years) ${ }^{a}$} \\
\hline $50-54$ (reference) & 1 & - \\
\hline $55-59$ & 2.14 & $1.31-3.51$ \\
\hline $60-64$ & 2.16 & $1.30-3.59$ \\
\hline $65-69$ & 2.71 & $1.52-4.84$ \\
\hline $70-74$ & 2.78 & $1.46-5.27$ \\
\hline $75-80$ & 4.73 & $2.46-9.10$ \\
\hline Men & 1.28 & $0.93-1.75$ \\
\hline \multicolumn{3}{|l|}{ Civil status } \\
\hline married (reference) & 1 & - \\
\hline single & 0.79 & $0.52-1.21$ \\
\hline divorced / separated & 0.95 & $0.67-1.36$ \\
\hline widow/-er & 1.01 & $0.63-1.61$ \\
\hline \multicolumn{3}{|l|}{ Occupation } \\
\hline Employed (reference) & 1 & - \\
\hline Social aid & 2.91 & $1.76-4.81$ \\
\hline Unemployed & 3.89 & $2.29-6.61$ \\
\hline At home/in education & 1.37 & $0.77-2.44$ \\
\hline Retired & 1.74 & $1.07-2.82$ \\
\hline Never smoked & 0.76 & $0.52-1.11$ \\
\hline BMI (kg/m2), per unit & 1.12 & $1.08-1.16$ \\
\hline \multicolumn{3}{|l|}{ Comorbidities $^{\mathrm{b}}$} \\
\hline Per each comorbidity & 1.86 & $1.68-2.07$ \\
\hline$\geq 2$ comorbidities versus $0-1$ comorbidity & 6.14 & 4.16-9.08 \\
\hline \multicolumn{3}{|l|}{ Specific subgroups $^{\mathrm{C}}$} \\
\hline Psychiatric diseases $^{d}$ & 1.14 & 0.83-1.59 \\
\hline Dementia & 0.83 & $0.35-2.01$ \\
\hline Cardiovascular diseases $^{\mathrm{e}}$ & 3.74 & $2.76-5.08$ \\
\hline Diabetes mellitus & 4.47 & $3.23-6.20$ \\
\hline Hypertension & 8.49 & $5.25-13.73$ \\
\hline Chronic pulmonary diseases ${ }^{\dagger}$ & 1.29 & $0.94-1.76$ \\
\hline Cancer & 0.97 & $0.65-1.45$ \\
\hline Chronic kidney disease & 3.96 & $2.71-5.80$ \\
\hline \multirow{2}{*}{\multicolumn{3}{|c|}{$\begin{array}{l}\text { Inappropriate prescribing } \\
\text { Patients aged } \geq 65 \text { years }\end{array}$}} \\
\hline & & \\
\hline Potentially inappropriate prescription & 3.72 & $1.47-9.44$ \\
\hline Potentially prescribing omission & 0.75 & $0.49-1.15$ \\
\hline \multicolumn{3}{|l|}{ Whole population } \\
\hline Potentially inappropriate prescription & 3.64 & $2.07-6.39$ \\
\hline Potentially prescribing omission & 0.81 & $0.59-1.11$ \\
\hline
\end{tabular}

The model was adjusted for age, gender, civil status, occupation. Random-effects model was used to account for treating physician.

Some statistically significant variables in Table 1 lost significance because of the mixed-effects analysis.

Abbreviations: $\mathrm{BMI}$, body mass index; $\mathrm{Cl}$, confidence interval; OR, odds ratio.

a for univariate and multivariate analysis $p$-value for trend $<0.001$.

${ }^{\mathrm{b}}$ list of 17 comorbidities listed in Appendix table, full description in [32].

${ }^{c}$ record of ever having the listed comorbidity.

depression, bipolar disorder, psychosis, schizophrenia, pervasive development disorder.

e history of transient ischemic attack, cerebral vascular accident, coronary artery disease, angina, myocardial infarction, congestive heart failure or peripheral vascular disease.

${ }^{f}$ chronic obstructive pulmonary disease, asthma, sleep apnea syndrome, sarcoidosis, pulmonary hypertension, bronchiectases, interstitial pulmonary disease or global respiratory insufficiency. 
Table 3. Multivariate categorical mixed-effects regression analysis for the association with number of drugs as a count variable.

\begin{tabular}{|c|c|c|}
\hline \multirow[b]{2}{*}{ Variable } & \multicolumn{2}{|c|}{ Number of drugs (count variable) } \\
\hline & $\begin{array}{l}\text { Incident rate } \\
\text { ratio }\end{array}$ & $95 \% \mathrm{Cl}$ \\
\hline \multicolumn{3}{|l|}{ Age (years) } \\
\hline $50-54$ (reference) & 1 & - \\
\hline $55-59$ & 1.27 & $1.11-1.45$ \\
\hline $60-64$ & 1.24 & $1.07-1.44$ \\
\hline $65-69$ & 1.30 & $1.10-1.53$ \\
\hline 70-74 & 1.29 & $1.09-1.53$ \\
\hline $75-80$ & 1.29 & $1.07-1.56$ \\
\hline Male & 1.11 & $1.01-1.22$ \\
\hline \multicolumn{3}{|l|}{ Civil status } \\
\hline married (reference) & 1 & - \\
\hline single & 0.94 & $0.81-1.08$ \\
\hline divorced / separated & 0.97 & $0.86-1.08$ \\
\hline widow/-er & 1.05 & $0.92-1.19$ \\
\hline \multicolumn{3}{|l|}{ Occupation } \\
\hline Employed (reference) & 1 & \\
\hline Social aid & 1.55 & $1.30-1.86$ \\
\hline Unemployed & 1.60 & $1.37-1.87$ \\
\hline At home/in education & 1.27 & $1.07-1.51$ \\
\hline Retired & 1.37 & $1.18-1.58$ \\
\hline Never smoked & 0.91 & $0.81-1.03$ \\
\hline BMI (kg/m2), per unit & 1.03 & $1.02-1.04$ \\
\hline \multicolumn{3}{|l|}{ Comorbidities $^{\mathrm{a}}$} \\
\hline Each comorbidity & 1.18 & $1.15-1.20$ \\
\hline$\geq 2$ comorbidities versus $0-1$ comorbidity & 1.91 & $1.72-2.13$ \\
\hline \multicolumn{3}{|l|}{ Specific subgroups $^{b}$} \\
\hline Psychiatric disease $^{c}$ & 1.11 & $1.00-1.23$ \\
\hline Dementia & 1.11 & $0.85-1.46$ \\
\hline Cardiovascular disease $^{d}$ & 1.48 & $1.35-1.63$ \\
\hline Diabetes mellitus & 1.58 & $1.45-1.72$ \\
\hline Hypertension & 2.10 & $1.87-2.36$ \\
\hline Chronic pulmonary disease $\mathrm{e}^{\mathrm{e}}$ & 1.15 & $1.04-1.26$ \\
\hline Cancer & 1.01 & $0.89-1.14$ \\
\hline Chronic kidney disease & 1.52 & $1.37-1.69$ \\
\hline \multicolumn{3}{|l|}{ Inappropriate prescribing } \\
\hline \multicolumn{3}{|l|}{ Patients aged $\geq 65$ years } \\
\hline Potentially inappropriate prescription & 1.35 & $1.12-1.64$ \\
\hline Potentially prescribing omission & 0.94 & $0.83-1.06$ \\
\hline \multicolumn{3}{|l|}{ Whole population } \\
\hline Potentially inappropriate prescription & 1.44 & $1.26-1.64$ \\
\hline Potentially prescribing omission & 0.90 & $0.81-1.00$ \\
\hline
\end{tabular}

The model was adjusted for age, gender, civil status, occupation. Random-effects model was used to account for treating physician.

Some statistically significant variables in Table 1 lost significance because of the mixed-effects analysis.

Abbreviations: BMI, body mass index; $\mathrm{Cl}$, confidence interval.

${ }^{a}$ list of 17 comorbidities listed in Appendix table, full description in [32].

${ }^{\mathrm{b}}$ record of ever having the listed comorbidity.

${ }^{c}$ depression, bipolar disorder, psychosis, schizophrenia, pervasive development disorder.

${ }^{d}$ history of transient ischemic attack, cerebral vascular accident, coronary artery disease, angina, myocardial infarction, congestive heart failure or peripheral vascular disease.

e chronic obstructive pulmonary disease, asthma, sleep apnea syndrome, sarcoidosis, pulmonary hypertension, bronchiectases, interstitial pulmonary disease or global respiratory insufficiency. 
Table 4. Number of patients with unfulfilled STOPP/START criteria.

\begin{tabular}{|c|c|c|}
\hline & $\begin{array}{l}\text { Patients } \\
\geq 65 \text { years, } \\
(n=426)\end{array}$ & $\begin{array}{c}\text { All patients } \\
(n=1002)\end{array}$ \\
\hline \multicolumn{3}{|l|}{ STOPP criteria } \\
\hline $\begin{array}{l}\text { A3. Any duplicate drug class prescription e.g. two concurrent } \\
\text { NSAIDs, SSRIs, loop diuretics, ACE inhibitors, anticoagulants }\end{array}$ & $5(1.2)$ & $7(0.7)$ \\
\hline B3. Beta-blocker in combination with verapamil or diltiazem & $1(0.2)$ & $4(0.4)$ \\
\hline B6. Loop diuretic as first-line treatment for hypertension & $1(0.2)$ & $4(0.4)$ \\
\hline C1. Long-term aspirin at doses greater than $160 \mathrm{mg}$ per day & $8(1.9)$ & $17(1.7)$ \\
\hline C7. Ticlopidine in any circumstances & $0(0.0)$ & $0(0.0)$ \\
\hline $\begin{array}{l}\text { J1. Sulphonylureas with a long duration of action with type } 2 \\
\text { diabetes mellitus }\end{array}$ & $12(2.8)$ & $37(3.7)$ \\
\hline J2. Thiazolidenediones in patients with documented heart failure & $0(0.0)$ & $0(0.0)$ \\
\hline \multicolumn{3}{|l|}{ START criteria } \\
\hline $\begin{array}{l}\text { A3. Antiplatelet therapy (aspirin or clopidogrel or prasugrel or } \\
\text { ticagrelor) with a documented history of coronary, cerebral or } \\
\text { peripheral vascular disease }\end{array}$ & $63(14.8)$ & $129(12.9)$ \\
\hline $\begin{array}{l}\text { A4. Antihypertensive therapy where systolic blood pressure } \\
\text { consistently }>160 \mathrm{mmHg} \text { and/or diastolic blood pressure } \\
\text { consistently }>90 \mathrm{mmHg} \text {; if systolic blood pressure }>140 \mathrm{mmHg} \\
\text { and /or diastolic blood pressure }>90 \mathrm{mmHg} \text {, if diabetic }\end{array}$ & $15(3.5)$ & $53(5.3)$ \\
\hline $\begin{array}{l}\text { A5. Statin therapy with a documented history of coronary, } \\
\text { cerebral or peripheral vascular disease, unless the patient's } \\
\text { status is end-of-life or age is }>85 \text { years. }\end{array}$ & $77(18.1)$ & $153(15.3)$ \\
\hline A7. Beta-blocker with ischaemic heart disease. & $43(10.1)$ & $72(7.2)$ \\
\hline
\end{tabular}

Abbreviations: STOPP, Screening Tool of Older People's Prescriptions; START, Screening Tool to Alert doctors to Right Treatment.

Data are presented as number (\%) of patients. 
Figure 1 Percentage of patients in ambulatory medicine receiving a particular number of drugs $(0$ to $\geq 10)$, stratified by a) age groups; b) number of comorbidities $(0,1,2,3-4,5-6, \geq 7)$, out of a list of 17 selected comorbidities, based on a large study by Higashi et al. [33] and the Charlson index [34], as previously defined [32].
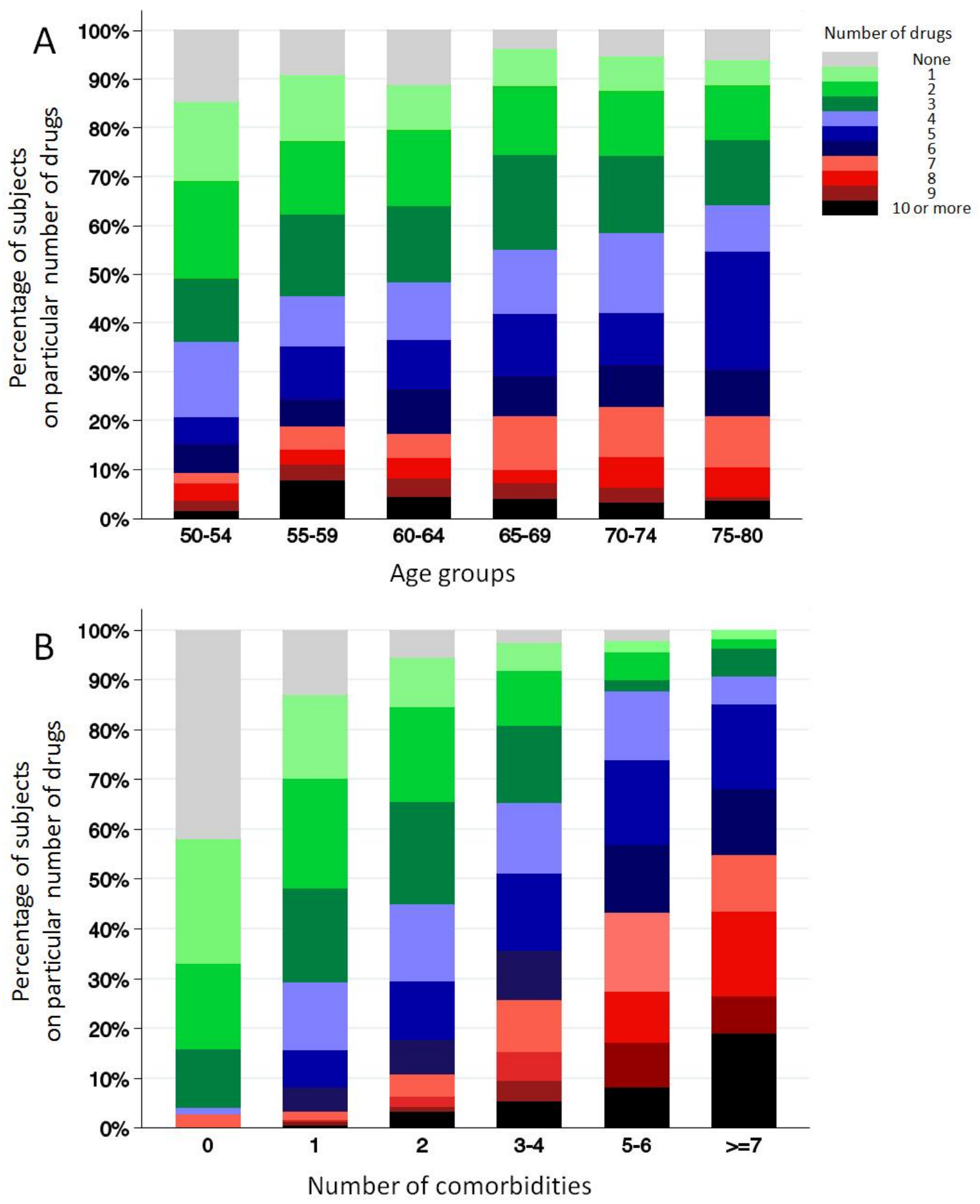